\title{
An Examination of Service Learning and Self-Efficacy for Masters Students Engaging in Substance Use Education
}

\author{
Stephanie Rose ${ }^{1}$, Johanna Thomas ${ }^{2}$, Samantha Christian ${ }^{3}$, Duston Morris ${ }^{4} \&$ Anita Sego ${ }^{4}$ \\ ${ }^{1}$ Department of Health Sciences-Addiction Studies, University of Central Arkansas \\ ${ }^{2}$ School of Social Work - University of Arkansas \\ ${ }^{3}$ Department of Social Sciences-Psychology, National Park College \\ ${ }^{4}$ Department of Health Science-Health Education, University of Central Arkansas \\ Correspondence: Stephanie Rose, Department of Health Sciences-Addiction Studies, University of Central \\ Arkansas, 201 Donaghey Avenue, Conway Arkansas, 72034, Email: srose3@uca.edu
}

Received: September 9, 2019

Accepted: November 1, 2019

Online Published: November 6, 2019

doi:10.5539/ijps.v11n4p82

URL: https://doi.org/10.5539/ijps.v11n4p82

\begin{abstract}
This study explored perceptions of social work students before and after a service-learning project in which they worked with clients with substance abuse issues. Two areas were explored: (1) social work students' perceptions of treating clients with substance use before and after the course "Addiction Treatment in Social Work" and the required service-learning project component; and (2) social work students' self-efficacy before and after the addiction, service-learning project. Data-collection occurred through a pre-post self-efficacy survey, a questionnaire about interests in working with clients struggling with addiction and a course assignment. Students also completed a demographic questionnaire. Data were analyzed using Dedoose for the qualitative data component and SPSS for the quantitative components. Overall, findings from the quantitative and qualitative analyses were very positive. Although there were no significant increases in self-efficacy from pre-post-test the average scores did increase nearly 3.5 points. Students also indicated they were more willing to work with both individuals and groups/families dealing with addiction issues. Moreover, students reported an increase in insight, skills, community engagement and meaningful experiences even though they reported having feelings of doubt initially. Based on the findings, specialized training and service-learning opportunities in addictions for social work students is beneficial. Training should target appropriate skills, the distinct needs of people who are suffering from substance abuse disorders, and self-reflection regarding perceptions of substance use disorders.
\end{abstract}

Keywords: self-efficacy, service-learning, social work, substance abuse

\section{Introduction}

As evidence-based interventions for substance abuse continue to emerge, the call for social workers to intervene increases. Both the National Association of Social Workers (NASW) and the Council on Social Work Education (CSWE) provide published guidelines to increase student and practitioner education in evidence-based practices for clients struggling with substance-use disorders (Wells, 2013). Not only does NASW provide specific publications addressing this need, the NASW Standards for Social Work Practice with Clients with Substance Use Disorders (2013) also discusses potential contributions social workers can make in the addiction field, particularly in terms of co-occurring disorders and providing evidence-based treatment. Although there is potential for social workers to contribute to the field, it is important they acquire adequate education and skills to provide effective treatment (NASW, 2013).

More than three quarters (87\%) of social workers reported working with clients struggling with substance use (Senreich, Ogden, \& Greenberg, 2017). Although these rates are high, social work students have minimal exposure to substance abuse treatment training. Nearly two-thirds (64\%) of Master of Social Work (MSW) programs offer substance-use-disorder treatment courses, while only twenty-five Bachelor of Social Work (BSW) programs offer the same (2017). In the majority both MSW and BSW programs, the substance abuse coursework is optional, rather than required (Petracchi, Weaver, Schelbe, \& Song, 2016). However, current research indicates substance use coursework is highly desired by both social workers who already work with clients who struggle with substance use issues and those who do not. In fact, practicing social workers reported 
pessimism about working with clients struggling with substance abuse due to perceived poor outcomes while social workers who received substance-abuse related coursework in their programs reported more positive experiences in working with clients struggling with substance abuse (Senreich, et al., 2017).

The current study explores the perceptions and self-efficacy of social work students before and after the completion of the social work course "Addiction Treatment in Social Work" and the required service-learning project where they worked with clients with substance abuse issues. It is posited substance abuse related coursework will positively impact social work students sense of self, as well as; their practice-approach and abilities. Furthermore, we speculate service-learning participation promotes student reflection and is an important aspect to prepare social worker students to properly address the complex issues of substance abuse (Slabbert, 2015). Service learning and self-efficacy are further explored in the proceeding sections.

\section{Study Questions}

The current study aims to examine the concepts of service learning and self-efficacy as they pertain to treating substance use for a cohort of Master of Social Work students. As such, the following research questions guided the data collection and analysis:

1. Will the willingness of students to work with people with substance abuse issues change from pre-post service learning project?

2. Will students' willingness to work with people with substance abuse issues change as a result of the service learning project?

3. Will there be a change in students' self-efficacy from pretest to posttest?

4. What knowledge do we gain from students' own interpretation of their service learning experience?

\section{Review of the Literature}

\subsection{The Growing problem of Substance Abuse}

The risk factors for the development of substance abuse issues can be found in the literature. Because the current study takes place in the United States, the context of this particular research study is mainly applicable to the growing problem of substance abuse in the United States. However, substance use and addiction are global issues that researchers are universally addressing and this study furthers the literature in this arena. Research indicates a plethora of factors may contribute to substance use, including, but not limited to, domestic violence, physical and/or sexual abuse, stress or anxiety, depression, and even adolescent behavioral issues (Slabbert, 2015). The effects of substance abuse are far-reaching, impacting the individual, family, friends, occupational well-being, relationships, and even their community (Slabbert, 2015). Approximately 21.7 million people aged 12 or older ( $8 \%$ of U.S. population) needed substance abuse treatment as of 2015. Young adults (18-24 years) have the highest need of substance abuse treatment amongst all adults (Bowen, 2015). Furthermore, current literature indicates a wide racial disparity in regard to substance abuse health and criminal justice outcomes (Bowen, 2015). For example, the rate of fatal cirrhosis in Hispanic males is double that of non-Hispanic males (Bowen, 2015). These same disparities are seen in the criminal justice system in which current literature indicates Black men are arrested three times the rate of non-Black men for possession of Marijuana (Bowen, 2015).

Because of the rise in drug use and drug use disorders, and the implementation of the Affordable Care Act (ACA), which created mental health and substance use parities, there is a greater need for social workers specifically trained in addiction treatment. The projected growth for addiction treatment clinicians was a staggering $21 \%$ by 2018 (Wilkey, 2013). Furthermore, nearly 2.3 million adults who needed specialty substance abuse treatment did not receive it (SAMSHA, 2016). Because of the growing demand for substance use practitioners, many individuals in need of treatment are either on waiting lists or do not end up receiving appropriate services (Wilkey, 2013), despite the majority of social workers (75\%) reported they had either previously worked with a client with substance use issues or were doing so currently (Wells, 2013).

\subsection{The Role of Social Workers in Substance Use Disorders and Treatment}

Social workers are often the first point of contact with individuals who are struggling with addiction and seeking help (Wilkey, 2013). Treating substance use disorders requires a specialized skillset for providing comprehensive care. As such, it is especially important for social workers to have the insight and the ability to challenge their own biases in relation to substance use disorders (Slabbert, 2015). Because so few social work students (both BSW and MSW) and practitioners are educated, or specialize, in substance use disorders or treatment specifically, few truly understand "triggers" and factors that affect abstinence. Moreover, many social workers find it difficult to empathize with clients working to obtain and/or maintain sobriety (Slabbert, 2015). 
Although substance abuse is often discussed and raised as an issue of importance for social work programs, there are minimal courses offered in addiction to prepare students for offering treatment (Wilkey, 2013). Current literature supports the need for increased holistic education regarding substance abuse for BSW and MSW students (Bowen, 2015).

In addition to the main pedagogy of the field internship in social work programs, community-based service-learning projects can provide social work students with opportunities to learn about treating substance use disorders as well as addressing mental health and related disparities in relation to substance abuse (Bowen, 2015). Service learning has an increased focus on service to the community and vulnerable populations. Not only does service-learning increase knowledge about a particular issue but also promotes increased self-efficacy and confidence of students' ability to work in a particular area (Williams, King, \& Koob, 2002).

\subsection{Service Learning and Self Efficacy}

The pedagogical approach of service learning is community-driven and allows students the opportunity to fully engage in their discipline or specialization in a community-based setting while meeting a need in their community. It is a type of high impact learning that provides students an opportunity to address real needs of a community, while receiving instructional oversight and support (Chen, Snell, \& Wu, 2018). John Dewey (1938) assisted in the development of the foundations of the service learning encouraging the idea that learning is enhanced through civic participation and real-community problem-solving (Gerstenblatt \& Gilbert, 2014). This type of learning is developmental for the student, particularly enhancing student-development of "the three R's," which include reality, reciprocity, and reflection (Petracchi, et al., 2016). For example, students provide a service via a service-learning project which provides opportunities for real-life practice (reality), they receive learning as they provide a needed service (reciprocity) and then are able to spend time carefully thinking about their experiences and knowledge (reflection) at the completion of the assignment in a safe and nurturing environment. This is important because students' psychological perceptions of service learning influence their perception of how service-learning effects their development of learned skills (Chen \& Wu, 2018).

The broad foundation of service learning easily lends itself to the values of the social work profession, making this an invaluable tool for educating future social workers. Service learning is a great compliment to the field internship as it shifts the focus from the individual to the collective (Petracchi, et al., 2016). Current research indicates social work students engaged in service-learning had higher levels of social justice, community-connection, insight of prejudices, appreciation of macro-practice, self-efficacy and overall satisfaction (Petracchi, et al., 2016). The community also benefits from community-empowerment and organizational satisfaction (Petracchi, et al., 2016). As such, the pedagogy of service-learning benefits both the student and the community through reciprocity.

The concept of self-efficacy is derived from Bandura's Social Cognitive Theory and focuses primarily on personal mastery, self-appraisal, and one's belief in personal ability to execute an intervention (Reeb et al., 2010). Increased self-efficacy is associated with increased likelihood of positive coping during times of distress (Hye \& Eui, 2017). Furthermore, increased self-efficacy is linked with performance improvement and proficiency (Reeb et al., 2010). Finally, self-efficacy assists with improving an overall sense of self-competence, as well as, improved motivation (Hutchison, 2012).

Current literature indicates self-efficacy is enhanced through service learning while also enhancing the practical skills learned in the classroom (Williams, 2002). Research indicates self-efficacy is enhanced by service-learning activities through the ability to practice and achieve mastery of a particular intervention while also having more meaningful hands on experiences (Reeb et al., 2010). Moreover, improving students' self-efficacy has been shown to improve self-evaluation of skills (Midgett, Hausheer, \& Doumas, 2016) as well as determine a learner's level of skills in terms of ability to cope with obstacles, level of effort, sustainability, and assist in the development and enhancement of their own empathy (Reeb et al., 2010).

In sum, the benefits of service learning for social work students are far reaching. Service learning not only increases a students' self-efficacy, but also assists the student to connect micro and mezzo issues to the macro level, which in turn changes a student's perceptions of their ability to affect change at the macro level (Reeb et al., 2010; Williams et al., 2002). Because of this, it is imperative research pairs the concepts of service learning and self-efficacy. The following sections will address the theoretical approach to the study, the methods and findings. 


\subsection{Theoretical Approach}

Grounded Theory was chosen as the theoretical approach and framework for the current study for two main reasons: a) because of the exploratory nature of the current study, and b) because of the lack of literature pertaining to service learning and self-efficacy for social work students working with individuals with substance abuse. The Grounded Theory approach is inductive, as opposed to deductive, which lends itself well to exploratory studies. Historically, Grounded Theory has been the favored approach to uncovering social relationships, groups of behaviors and social processes (Noble \& Mitchell, 2016). It had been used to better understand patterns of actual human behavior, as opposed to those that are hypothesized. Regardless of study size, a Grounded Theory approach is particularly adept at allowing researchers to identify inter-relationships between structural, social, and social-psychological processing, enabling the researcher to gain critical insights about patterns of human behavior and their practical implications (Noble \& Mitchell, 2016). The purpose of Grounded Theory research in education and social services is to allow researchers to develop new concepts and theories of education-related phenomena, where those concepts and theories are firmly grounded in real data. It also allows for the emergence of original, robust findings that are closely tied to the generated data.

Grounded Theory is a valuable research method used to capture and understand health care experiences of both people giving and receiving services (Foley \& Timonen, 2015). It aims to discover problems in a given environment and identify how people handle these problems. It is helpful in developing an understanding of a phenomena that cannot be explained with existing theories and paradigms. This methodology offers a systematic and rigorous process of data collection and data analysis. Therefore, social issues can be studied in a great level of depth, making Grounded Theory one of the most appropriate methodologies for social research and for the current research study (Foley \& Timonen, 2015). Grounded Theory provides an opportunity to explore the reciprocal relationship between the data and literature, which can assist with linking these aspects (Grinnel \& Unrau, 2005). The collected qualitative data in this study was subjected to three different rounds of color-coding. The first level of coding was used to identify overall concepts and categories. These overall themes were colored green and included any type of student response to their service-learning project. The second level of coding used the color red and differentiated between student feelings and responses pre and post of the implementation of the prevention project. The last round of color-coding used yellow to identify the students' perceived benefits of the service-learning project. Dedoose was used in order to identify overall presenting themes.

\section{Methodology}

\subsection{Participants}

Students included in the study came from one accredited MSW program in a mid-size metropolitan university in the Southern United States. All students were enrolled in a substance use class, wherein each of the students completed a service-learning project around substance use. The study was approved through the University Institutional Review Board. All qualitative and quantitative data for the study were collected from students during regular class periods throughout the semester. Because the primary instructor for the course was also one of the main researchers, on the first day of class, a neutral party presented students with the informed consent documents and read a script to students providing them with information about the study prior to obtaining consent. The neutral party did not provide any information regarding student participation in the study to the research team. The neutral party provided students with the pre and post data-collection documents. This person was available for students throughout the semester and kept all student data (other than graded assignments) until course completion. Concerns regarding a conflict of interest were considered since the primary researcher was the same as the course instructor (insider researcher). The costs and benefits of being an insider researcher were carefully considered. As such, some of the benefits of being an insider researcher included "instant" rapport and shared context of reference regarding the topic. Some points of concern included possible pre-conceptions from both the instructor and the students (Mercer, 2007). Keeping this knowledge in mind, the primary researcher was careful to adhere to boundaries and ensure they were maintained, including a policy of not discussing the research project with the students. Furthermore, ethical considerations were considered and acted upon when identifying the research methods, including data collection, sampling, and analysis. Upholding ethical standards, and taking necessary precautionary measures during the study helped to decrease any issues that could have arisen that resulted in concerns for participants (Collaborative Institutional Training Initiative [CITI], 2004). Protecting participants was of the utmost importance both in developing and carrying out the study to ensure confidentiality and to reduce the chance for harm.

The convenience sample consisted of seven graduate social work students. The sample of students were almost exclusively female, including six females and one male. Two students reported being in their Foundation (first) 
year of the program, while five reported being in their concentration (second or advanced) year of the program. The majority of students were white $(\mathrm{n}=5)$, while only two identified as Black. Employment among the seven students were nearly equally split between being unemployed $(n=2)$, employed part time $(n=2)$ and employed full time $(\mathrm{n}=3)$.

Data for the current study came from several different instruments. Student demographic information was collected through a self-administered demographic survey. Students were also given a self-administered self-efficacy survey (pre and post service learning project), a reflective journaling assignment, and a questionnaire that asked about interest in working with clients struggling with addiction. Student grade information was also collected as well as qualitative data from reflective journaling course assignments throughout the course.

\subsection{Instrumentation}

Students were given the The Social Work Self-Efficacy Scale (Holden, Meenaghan, Anastas, \& Metrey, 2007) pre- and post-service learning project. The instrument is a 52-question survey that asks respondents to rate their perception of self-efficacy in practice. Students were also given another short survey which contained just four questions. For the first two questions students were asked to rate their response on a 5-point Likert scale $(1=$ not interested to $5=$ very interested). These questions were: 1) What is your interest level in working with individuals with addiction? and 2) What is your interest level in working with groups and/or families who struggle with addiction? The two other questions were open ended questions and asked students: 1) What are some reasons that you would or would not want to work with individuals, groups and/or families who struggle with addiction? and 2) What are some reasons that you have identified that would lead you to work with individuals, groups and/or families who struggle with addiction? Lastly, upon completion of the students' service learning prevention project, they were asked to complete a journal assignment. This reflective journal assignment asked the students to: 1) Discuss related feelings they experienced throughout the course of the project. 2) Discuss any difficulties that they encountered during the project, and 3) Discuss outcomes, experiences and perception of the audience-response.

\subsection{Data Analysis}

Data from the course assignments were analyzed using qualitative data analysis software, Dedoose (2018), which supports Grounded Theory thematic coding. Qualitative data collection was appropriate for this study because this method is the best strategy for gathering in-depth information from students about their observations of, and feelings related to, improving their service learning project. The interview transcripts were best handled using qualitative software that assisted researchers with coding the data and identifying themes of the three data collection methods (self-efficacy scale, journaling assignment and open-ended question survey). Using Dedoose enabled researchers to triangulate and corroborate the data, as well as identify overlapping data themes from the three sources. The open-ended questions in the surveys and interviews elicited participants' perceptions and attitudes regarding their service-learning project. Responses to the journaling assignments, as well as, the pre and post test questions from the instruments were collected through a document that was emailed to the students. Data from those instruments were entered into Dedoose in order to complete the qualitative analysis. Within Dedoose each participant was assigned an individual identification number to distinguish participant responses (e.g., P1, P2, etc.). From there, thematic coding of the qualitative data involved typifying and breaking data down by identifying related text and themes to make collected data more: a) researchable, b) manageable, c) interpretable, and d) manipulatable. These procedures rendered the data into a whole and led to additional findings and discovery of new relationships among the data (Evers, 2016). The final sample consisted of six graduate students, as one of the original seven students completed the pre-test but did not complete the course, therefore was excluded from the study. The sample range for appropriate qualitative data saturation can range from five to 25 , so six participants is still within the acceptable range for reliable qualitative results (Mason, 2012).

Quantitative data from the Social Work Self-Efficacy Survey were analyzed using PSPP (GNU Project, 2015). The survey consisted of 52 Likert-scale questions regarding the student's confidence in performing specific tasks related to social work. Pretest and posttest surveys were distributed and completed during class. Data from the surveys were then manually entered into PSPP. The students' pretest and posttest surveys were then manually paired with their qualitative surveys using the same individual identification number provided on both surveys. Following data collection, a paired samples t-test was conducted on the self-efficacy survey to assess for a significant difference in the overall mean score from pre to posttest. 


\section{Results}

Using a five-point Likert scale $(1=$ not interested to $5=$ very interested $)$, students were asked to rate the following questions before and after their involvement in the service-learning project: 1) What is your interest level in working with individuals with addiction? and 2) What is your interest level in working with groups and/or families who struggle with addiction? The findings from these questions indicated that students were "interested" to "very interested" in working with individuals with addiction both before and after the service learning project. The students reported similar results for working with groups and/or families struggling with addiction. For this question, more of the students reported being "very interested" which was a slight increase from pretest to posttest.

Following the open-ended questions, a paired samples t-test was conducted to compare the average pre and post test scores from the Social Work Efficacy Scale. All of the data was normally distributed. Although the sample size was small, current research indicates paired-samples t-tests can be utilized with very small samples $(<12)$, providing acceptable power and Type I error rates close to 5\% (De Winter, 2013). Findings from the t-test analyses (Figure 1) indicated there was not a significant difference in self-efficacy from pre $(\mathrm{M}=85.25, \mathrm{SD}=8.74)$ to posttest $(\mathrm{M}=88.56, \mathrm{SD}=7.96 ; \mathrm{t}=-1.19, \mathrm{p} .=0.280)$. However, it should be noted that although the difference from pre to post was not significant, many students saw a sizeable increase in the self-efficacy score from pre-post anywhere from five to 20 points, and by 3.5 points, on average, overall.



Figure 1. Social Work Self Efficacy Scores from Pre-Posttest by Student

Following the t-test analysis qualitative data were analyzed. The two qualitative questions: 1) What is your willingness to work with individuals who have addiction issues? and 2) What is your willingness to work with families/groups who have addiction issues? Were analyzed first. The students' full responses to these questions are provided in the tables below. Several students reported having personal experiences, such as, a family member struggling with addiction as reason for not wanting to work in the addiction field. However, when students were asked this question after the prevention project, there were some changed perceptions in regard to reasons they would want to work in the addiction field, particularly having an increased understanding of the complex issues related to addiction (Table 1). The responses align with the literature on service learning. For example, some students continued to identify individual experiences as factors affecting their willingness to work with families/groups who have addiction issues. An increased insight of prejudices is an identified benefit of service-learning (Petracchi, et al., 2016). Students who reported an increased willingness to work in the substance abuse field reported reasons related to increased insight of issues related to substance abuse, as well as, self-evaluation of skills in that they identified a need for increased training. Both increased insight and self-evaluation of skills are also identified benefits of service learning in the extant literature (Midgett et al., 2016). 
Table 1. Willingness to Work with Individuals who Struggle with Addiction by Student

\begin{tabular}{|c|c|c|}
\hline Participant Number & Response Q1 (pre) & Response Q1 (post) \\
\hline \multirow{5}{*}{01} & "I have some family members & "I want to reduce the stigma \\
\hline & currently struggling to overcome & associated with substance misuse \\
\hline & addiction. There is a & and empower families to support \\
\hline & high-prevalence rate and a lack of & their family member struggling \\
\hline & dual-diagnosis treatment centers." & with addiction." \\
\hline \multirow{7}{*}{02} & "I would want to work with them & "I want to work with individuals, \\
\hline & because they are a very stigmatized & groups and families who struggle \\
\hline & and misunderstood group of & \\
\hline & people." & with addiction because they are \\
\hline & & often misunderstood and a \\
\hline & & stigmatized, vulnerable \\
\hline & & population." \\
\hline \multirow{6}{*}{03} & "Based on a very close experience & "It is so hard for me when I see \\
\hline & I've had with loved ones being & clients not making progress or \\
\hline & continuously hurt by addiction, I & relapsing. I know that's unfair to \\
\hline & get very angry and frustrated when & the clients, but that's why I would \\
\hline & I think about/attempt to understand & not want to work in this area with \\
\hline & addiction." & adults. \\
\hline \multirow{3}{*}{04} & "I have previous experience in & "I would because I see now how \\
\hline & working with my family members & devastating this disease is." \\
\hline & with addictions.” & \\
\hline \multirow{11}{*}{05} & "I would feel personal defeat if the & "I would want to work with this \\
\hline & individual did not successfully & population because people could be \\
\hline & reach their set goals. I would be & misusing/abusing substances \\
\hline & hesitant because of my lack of & without knowing they are. I'd like \\
\hline & experience with drugs/alcohol. I & to help with awareness and \\
\hline & would because of personal & prevention. I have no severe \\
\hline & experience seeing the effects of & experience with drugs/alcohol \\
\hline & different addictions and I want to & myself. I feel I would need more \\
\hline & learn how to better serve this & training than just a class to feel \\
\hline & community." & expert-confidence working with \\
\hline & & them specifically.” \\
\hline \multirow[t]{5}{*}{06} & "I would want to work with & "I want to work with individuals \\
\hline & individuals/families who struggle & who struggle with addiction \\
\hline & with addiction because I have & because I have seen it first hand \\
\hline & always had an interest in them due & and how it has effected an \\
\hline & to personal family-struggles." & individual and family's life." \\
\hline
\end{tabular}

Findings from the second question (Table 2) were similar to those of the first question. Although some students identified personal experiences with addiction, other students mentioned this as a reason for wanting to increase their involvement within this field. 
Table 2. Willingness to Work with Families/Groups who Struggle with Addiction by Student

\begin{tabular}{|c|c|c|}
\hline Participant Number & Response Q2 (pre) & Response Q2 (post) \\
\hline 01 & $\begin{array}{c}\text { "I have family members impacted } \\
\text { by addiction and there is a high } \\
\text { prevalence rate." }\end{array}$ & $\begin{array}{c}\text { "Personal experience with family } \\
\text { members." }\end{array}$ \\
\hline 02 & $\begin{array}{l}\text { "I have been interested in the } \\
\text { effects of drug use since I was a } \\
\text { teenager." }\end{array}$ & $\begin{array}{c}\text { "I have been interested in addiction } \\
\text { and its effects on the body for a } \\
\text { longtime." }\end{array}$ \\
\hline 03 & $\begin{array}{l}\text { "Where there are addicts, there are } \\
\text { people who are hurt by addicts. My } \\
\text { heart is very passionate toward } \\
\text { children with parents that are } \\
\text { addicted to substances." }\end{array}$ & $\begin{array}{l}\text { "I'm passionate about working with } \\
\text { children who have experienced } \\
\text { trauma. Many children of addicts } \\
\text { have experienced trauma." }\end{array}$ \\
\hline 04 & $\begin{array}{l}\text { "Because my Father was an } \\
\text { alcoholic and addict. I believe if he } \\
\text { had accessed continual care, his } \\
\text { addictions may have subsided." }\end{array}$ & $\begin{array}{c}\text { "I would because my Father } \\
\text { struggled with addiction until he } \\
\text { died." }\end{array}$ \\
\hline 05 & $\begin{array}{l}\text { "Personal experiences seeing the } \\
\text { effects of different addictions. } \\
\text { Fetal Alcohol Syndrome is } \\
\text { stigmatized. I want to help } \\
\text { destigmatize it!" }\end{array}$ & $\begin{array}{l}\text { "The statistics are alarming. My } \\
\text { own family could be misusing } \\
\text { prescriptions without knowing they } \\
\text { are." }\end{array}$ \\
\hline 06 & "Personal family reasons." & $\begin{array}{l}\text { "Some reasons that lead me to } \\
\text { work with individuals who struggle } \\
\text { with addiction would be seeing my } \\
\text { family struggle with it." }\end{array}$ \\
\hline
\end{tabular}

For the journal assignment students were asked to: 1) Discuss feelings related to their experiences throughout the course of their project (Table 3), and 2) Discuss their outcomes, experiences and perception of the audience-response (Table 4). Findings from the qualitative analysis showed students initially indicated they had feelings of self-doubt, but also felt they had increased insight and improved skills. Among the three main themes, increased insight was by far the predominant theme $(n=5)$ followed by improved skill $(n=4)$ and initial self-doubt $(\mathrm{n}=3)$. One of the students (P3) noted "the research can get very overwhelming", while another said, "I noticed several prevention programs start out strong, but eventually began to get lost amongst the list of duties" (P1). However, some of the other comments were more positive including "It was a good experience and I felt like I made a small difference in the community through my work" (P4) and "I received positive feedback from school administrators" (P1). Per the literature, service learning assists with self-efficacy, which assists with improving an overall sense of self-competence, as well as, improved motivation (Hutchison, 2012). Students repeatedly mentioned they had learned more about substance use disorders and addiction, which improved their knowledge about what the needs are in regard to substance abuse. They also mentioned receiving positive feedback from professionals in the community, thus assisting with improved self-competence and motivation. Lastly, improved community or macro skills were also mentioned, particularly in regard to a better understanding of the community's needs. Community and organizational empowerment and satisfaction have been found to be benefits of service learning (Petracchi, et al., 2016). 
Table 3. Reflections on Feelings Experienced During Project by Student

\begin{tabular}{|c|c|}
\hline Theme & Responses by participants $(P)$ \\
\hline \multirow{3}{*}{ Initial Self Doubt } & "The research can get very overwhelming..." (P3) \\
\hline & $\begin{array}{l}\text { "It was difficult to find research on substance use in } \\
\text { the elderly population as they are often left out of } \\
\text { research in general..." (P1) }\end{array}$ \\
\hline & $\begin{array}{l}\text { "When I first read about the prevention project, I was } \\
\text { afraid it would take an enormous amount of time, and } \\
\text { that it would be intimidating to present." (P1) }\end{array}$ \\
\hline \multirow[t]{2}{*}{ Increased Insight } & $\begin{array}{c}\text { "My personal experience implementing the prevention } \\
\text { project helped me gain insight...." (P1) }\end{array}$ \\
\hline & $\begin{array}{c}\text { "I've noticed that several prevention programs start out } \\
\text { strong, but eventually began to get lost amongst } \\
\text { the list of duties..." (P1) }\end{array}$ \\
\hline
\end{tabular}

"The prevention plan project was eye-opening to me."

Improved Skill

"Reading the facts on teen alcohol abuse was heart breaking to me." (P1)

“...this project stemmed from an overall interest in relating all aspects of it to the social welfare of older adults." (P1)

"I received positive feedback from school administrators." (P1)

"I have learned very knowledgeable things while working on this project: what the community is doing about preventing teens on alcohol use, local resources and many websites with hotlines and links for support." (P2)

"It was a good experience and I felt like I made a small difference in the community through my work." (P4)

"I became more comfortable so it was not intimidating to present the information." (P5)

\footnotetext{
When asked to discuss their outcomes, experiences and perception of the audience-response, the two primary themes that emerged from the analysis were community-engagement and meaningful experiences. Amongst participants these themes were roughly even with half identifying community engagement and half meaningful experiences (Table 4). These findings align with existing literature based on the increased focus that service learning places on the community (Williams, et al., 2002). Furthermore, a great deal of focus is placed on the needs of the community (Petracchi, et al., 2016), as well as, real-community problem-solving (Gerstenblatt \& Gilbert, 2014). Students shared overall perspectives about "feeling good" about what they were able to provide to their communities, as well as, having a richer understanding of their community's needs. Meaningful experiences via practical application of skills through service learning is another noted benefit (Reeb et al., 2010).
} 
Student responses provided a theme regarding having meaningful experiences about their service-learning project and this was noted, even if they felt it "made a small difference."

Table 4. Reflections on Experiences and Perceptions of Audience Response to Project

Theme

Community Engagement

Responses by Participant $(P)$

"I spoke with (DCFS Worker) and asked her if I could keep teen alcohol prevention brochures in her parenting class. She was so excited and loved the brochures." (P1)

"So far, there has been a positive response to the brochures. There has been some talk in the lobby about how much helpful the information is. I have seen clients take them home to "give my son/daughter/sister/friend."

"I took my brochures to the (community organization). I learned a few things about (Gerontology-Community Advocacy Group). The (director) was appreciative of the brochures." (P1)

"I knew I wanted to give back to the nonprofit (recovery center) because I greatly enjoyed my time interning there...I went to center and met with one of the directors. I explained who I was and what I was trying to do in the community. She graciously accepted the brochures and told me they would be a great help for those recovering from meth abuse. Some of the residents of the center welcomed me and seemed interested in my cause." (P2)

"The brochures were also, given to the (city) drug court coordinators and school professionals. I received relatively positive feedback from school administrators...Teachers were also excited to learn that there would be an opportunity to learn about behavioral cues or change in appearance which may be helpful to early detect and advocate for a teen exhibiting mild adaptive behaviors or in high-risk environments." (P2)

Meaningful Experience

"I felt good about leaving my brochures. I hope parent will take them and educate their teens on prevention of alcohol." (P1)

"I know that in most cases, the addict has to decide for themselves to change. However, it is my belief that any piece of information given can plant a seed of hope in the minds of each person who reads the brochure." (P2) 
"I knew it would be a great way to not only raise awareness to that community of advocates about prevention but also to promote the Drug Take Back Day and Prescription Drug Abuse Prevention Summit." (P3)

"It is my hope that these brochures and the information given to the therapists will benefit them as they talk

with adolescent patients. As a Mental Health Technician, it is my plan to do a group therapy session to target e-cig and vape prevention. I would expect the adolescents to ask questions during the group session, and to also say that vapes aren't harmful. This is because of how intensely vape companies target teens. While teaching prevention to teens normally seems like they are not receptive, I think some of the adolescents would be receptive." (P4)

"It was a good experience and I felt like I made a small difference in the community through my work." (P5)

"The outcome of this event led me to understand the importance of data and record keeping, since research is limited in the community about dual-focused services having a person in charge of reporting analytics to school districts can expand information to further support the advancement in dual-focused programs being implemented in public schools. While developing this project I recognized that the integrity of these students is shaped from their experiences; therefore, if we acknowledge mental health and substance abuse as a stigma we will continue to ignore ways to empower individuals from discovering the resilience within themselves to fight against the adversities placing them at high-risk for developing an addiction." ( $\mathrm{P} 1)$

\section{Discussion}

Overall, findings from both the quantitative and qualitative data analyses were very positive. Although there were no significant increases in self-efficacy from pre-posttest the average scores did increase nearly 3.5 points overall. Students also indicated they were more willing to work with both individuals and groups/families dealing with addiction issues. Moreover, students reported an increase in insight, skills, community engagement and meaningful experiences even though they reported having feelings of doubt initially.

Service learning has been associated with a positive impact on sense of self and practice abilities (Slabbert, 2015), as well as, increased levels of social justice and insight of prejudices (Petracchi, et al., 2016). This was further demonstrated when students mentioned the sustainability of prevention programs, as well as, the lack of services and information for the older population in relation to prevention efforts. Services, or lack thereof, for 
addressing adversity and stigma were also identified in student-feedback. In-terms of improved skills, students provided feedback about feeling overall more comfortable and not as intimidated with their efforts.

Although there were many positive findings from the study, there was not an overall significant difference from pre to posttest on the Social Work Self-Efficacy Survey. It would appear there are several possibilities for this outcome. First, the sample size was very small for quantitative analysis which can decrease the likelihood of determining a statistically significant difference. Second, students may have suffered from response fatigue, as the instrument contained 52 questions (Rolstad, Adler, \& Rydén, 2011). In addition, students may have over assessed their ability at the beginning of the course whereas their answers at the end of the course may have been more reflective of their actual ability. The findings from the qualitative analysis would appear to support this. Students indicated they had increased insight about their experiences and abilities, yet they also indicated they had some self-doubt and some anxiety about their abilities which may have been reflected in their self-efficacy survey either at pre or posttest. Another consideration is that providing students with open-ended questions during qualitative data collection may have allowed them an opportunity to provide increased insight, as the extents of feelings related to the project were elicited. Using open-ended questions may have assisted with decreasing constraints regarding responses in the standardized instrument (Grinnell \& Unrau, 2005). The responses were also gathered from both a survey, as well as, a journaling assignment because responses to open-ended questions can decrease response rates (Grinnell \& Unrau, 2005); however, because the journal activity was a pre-planned assignment, students had ample time to respond.

\section{Limitations}

This study does have some overall limitations. Since social work students were the focus of the study, the results may not be generalizable to other student populations. Furthermore, the sample size was very small and mostly homogenous, further limiting generalizability and significant quantitative analysis. It would also appear the qualitative and quantitative instruments produced different results with students identifying more self-efficacy in the qualitative comments rather than in the self-administered survey. Although this is certainly a limitation, it provides insight into how to best approach understanding the impact of service learning, especially for such a small group of learners. More research is needed to understand how these instruments differ and how to create qualitative instruments that complement the quantitative scales.

It is also of importance to note some of the potential constraints when utilizing service learning. Some of these can include time constraints, willingness of agencies to collaborate with students and the school, as well as, additional time on the instructor's part for preparation and oversight of students' projects (Kricsfalusy. George \& Reed, 2018). These components should be considered when using service-learning projects for courses.

\section{Implications}

Based on the findings from this study and the literature review, it would appear specialized training in addictions for social work students is beneficial. Training should target appropriate skills, the distinct needs of people who are suffering from substance abuse disorders, and self-reflection regarding perceptions of substance use disorders (Slabbert, 2015). Based on the qualitative findings, increased community and service-based learning opportunities should be encouraged as part of student learning modules for social work students. Overall social work students reported enjoying the experience, felt their projects were worthwhile, and reported increased insight and skills. Minimal research exists regarding reflective learning related to substance abuse disorders in social work programs. Based on the reported increase in insight of the students who participated in the current study, it is recommended social work students who are working with clients struggling with substance use find training to gain insight into their own views of substance abuse in order to provide a non-judgmental and empathetic services. Lastly, minimal research has been conducted regarding self-efficacy in the field of counseling (Midgett et al., 2016). As such, studies that examine self-efficacy and perceived self-efficacy are warranted (Williams et al. 2002). Furthermore, Schools of Social Work are behind with the implementation of service-learning projects that enhance self-efficacy. More opportunities for service-learning and related research is encouraged (Williams et al. 2002).

Limitations notwithstanding, the current study adds to the research on training social work students in addiction work and creating space for better and more learning opportunities through service learning. Social workers are uniquely poised to address substance use disorders and the addiction crisis facing the United States. Moreover, social workers have an ethical obligation to promote justice and decrease discrimination. The educational experiences of social workers place them in a position to advocate for access to healthcare and treatment (NASW, 2017). Social workers' direct practice experience can provide valuable input to policymakers regarding addiction. Likewise, these policies influence treatment opportunities for social workers in the addiction field (Powell, 
Garrow, Woodford, \& Perron, 2013). Social work ethics include advocacy for policies that improve conditions for clients (NASW, 2017). When social workers do not exercise the opportunity to influence policy, adverse policies may be reinforced (Powell et. al 2013).

\section{References}

Bowen, E.A. \& Walton, Q.L. (2015). Disparities and the social determinants of mental health and addictions: opportunities for multifaceted social work response, Health \& Social Work, 40(3), e59-e65. https://doi.org/10.1093/hsw/hlv034

Chen, T. Snell, R.S. \& Wu, C.X. (2018). Comparing the Effects of Service-Learning Versus Nonservice Learning Project Experiences on Service Leadership Emergence and Meaning Schema Transformation, Academy of $\begin{array}{lllll}\text { Management Learning \& } \quad \text { Education, } & \text { 17(4), }\end{array}$ https://doi-org.ucark.idm.oclc.org/10.5465/amle.2016.0309Dedoose. (2018). Great research made easy. Retrieved from https://www.dedoose.com/

Collaborative Institutional Training Initiative. (2004). Human research, basic course. Retrieved from https://www.citiprogram.org/members/index.cfm?pageID $=181$

De Winter (2013). Using the Student's t-test with Extremely Small Sample Sizes. Practical Assessment Research and Evaluation, 18, 1-12, Retrieved from https://pareonline.net/getvn.asp? $\mathrm{v}=18 \& \mathrm{n}=10$

Evers, J. C. (2016). Elaborating on thick analysis: About thoroughness and creativity in qualitative analysis. Forum: Qualitative Social Research, 17(1), 152-172. Retrieved from http://www.qualitative-research.net

Foley, G. \& Timonen, V. (2015). Using Grounded Theory Method to Capture and Analyze Health Care Experiences. Health services research, 50, 1195-1210. https://doi.org/10.1111/1475-6773.12275

Gerstenblatt, P. \& Gilbert, D.J., (2014). Framing Service Learning in Social Work: An Interdisciplinary Elective Courses Embedded within a University-Community Partnership, Social Work Education, 33(8), 1037-1053. https://doi-org.ucark.idm.oclc.org/10.1080/02615479.2014.935731

GNU Project (2015). GNU PSPP (Version 0.8.5) [Computer Software]. Free Software Foundation. Boston, MA. Available from: https://www.gnu.org/software/pspp/

Holden, G., Meenaghan, T., Anastas, J. \& Metrey, G. (2007). The Social Work Self-Efficacy Scale. Retrieved from https://archive.nyu.edu/handle/2451/23613

Hutchison, E. (2012). Essentials of Human Behavior: integrating person, environment, and the life course. Los Angeles, CA: Sage.

Hye, R.L. \& Eui, J.J. (2017). Therapeutic role of Player Self-Efficacy in Online Gaming. Social Behavior \& Personality: An international Journal, 45, 1475-1484. https://doi.org/10.2224/sbp.6334

Kricsfalusy, v., George3, C. \& Reed, M.G. (2018). Integrating problem-and project-based learning opportunities: assessing outcomes of field course in environment and sustainability, Environmental Education Research, 24(4), 593-610. https://doi.org/10.1080/13504622.2016.1269874

Mason, W. A. \& Spoth, R. L. (2012). Sequence of alcohol involvement from early onset to young adult alcohol abuse: Differential predictors and moderation by family-focused preventive intervention. Addiction, 107, 2137-2148. https://doi.org/10.1111/j.1360-0443.2012.03987.x

Midgett, A., Hausheer, R. \& Doumas, D.M. (2016). Training Counseling Students to Develop Group Leadership Self-Efficacy and Multicultural Competence Through Service Learning. Journal for Specialists in Group Work, 41, 262-282. https://doi.org/10.1080/01933922.2016.1186765

Mercer, J. (2007). The challenges of insider research in educational institutions: wielding a double-edged sword and resolving delicate dilemmas, Oxford Review of Education, 33(1), 1-17. Retrieved from https://search.ebscohost.com/login.aspx?direct=true\&db=eue\&AN=507956298\&site=eds-live\&scope=site

National Association of Social Workers. (2017). Code of Ethics. Washington, D.C.: NASW

National Association of Social Workers. (2013). NASW standards for social work practice with clients with substance use disorders. Washington, D.C.: NASW.

Noble, H. \& Mitchell G. (2016). What is grounded theory? Evidence Based Nursing, 19, 34-35. Retrieved May 29, 2019, from https://ebn.bmj.com/content/19/2/34 
Petracchi, H.E., Weaver, A., Schelbe, L. \& Song, H. (2016). Service Learning in Baccalaureate Social Work Education: Results of a National Survey of Accredited Programs. Journal of Social Work Education, 52(3), 325-336, https://doi-org.ucark.idm.oclc.org/10.1080/10437797.2016.1174628

Powell, T., Garrow, E., Woodford, M. \& Perron, B. (2013). Policymaking Opportunities for Direct Practice Social Workers in Mental Health and Addiction Services. Retrieved from file://D:/Documents/2227-Article\%20Text-22873-1-10-20131126.pdf

Reeb, R.N., Folger, S.F., Langsner, S., Ryan, C., \& Crouse, J. (2010). Self-Efficacy in Service-Learning Community Action Research: Theory, Research, and Practice. American Journal of Community Psychology, 46, 459-471. https://doi.org/10.1007/s10464-010-9342-9

Rolstad, S., Adler, J. \& Rydén. (2011). Response burden and questionnaire length: is shorter better? A review and meta-analysis, Value in Health, 14, 1101-1108, https://doi.org/10.1016/j.jval.2011.06.003

Senreich, E., Ogden, L.P., \& Greenberg, J.P. (2017). Enhancing Social Work Students' Knowledge and Attitudes Regarding Substance-Using Clients through SBIRT Training. Journal of Social Work Education, 53(2), 260-275. https://doi.org/10.1080/10437797.2016.1266979

Slabbert, I. (2015) Reflective learning in social work education in the field of substance abuse. Social Work/Maatskaplike Werk, 51, 549-591. doi:10.15270/51-4-485

Substance Abuse and Mental Health Services Administration. (2016). The CBHSQ Report: America's need for and receipt of substance use treatment in 2015. National Survey on Drug Use and Health. Retrieved on June 16, 2019 from:https://www.samhsa.gov/data/sites/default/files/report_2716/ShortReport-2716.html

Wells, E., Kristman-Valente, A., Peavy, K., \& Jackson, T. (2013). Social workers and delivery of evidence-based psychosocial treatments for substance use disorders. Bethesda, MD: National Center for Biotechnology Information. doi:10.1080/19371918.2013.759033

Wilkey, C., Lundgren, L. \& Amodeo, M. (2013). Addiction training in social work schools: a nationwide analysis. Journal of social work practice in the addictions, 13, 192-210. doi:10.1080/1533256X.2013.785872

Williams, N.R., King, M. \& Koob, J.J. (2002). Social Work Students Go to Camp: The Effects of Service on Perceived Self-Efficacy. Journal of Teaching in Social Work, 22, 55-70. doi: 10.1300/J067v22n03_05.

\section{Copyrights}

Copyright for this article is retained by the author(s), with first publication rights granted to the journal.

This is an open-access article distributed under the terms and conditions of the Creative Commons Attribution license (http://creativecommons.org/licenses/by/4.0/). 